\title{
Perancangan Tata Kelola Teknologi Informasi Menggunakan Kerangka Kerja COBIT 2019 di DISKOMINFOSAN Kabupaten Sukabumi
}

\author{
Muhamad Gilang Ginanjar ${ }^{1}$, Luthfi Ramadani ${ }^{2}$, Ryan Adhitya Nugraha ${ }^{3}$ \\ Email : mgilangginanjar@student.telkomuniversity..ac.id, luthfi@telkomuniversity.ac.id, \\ ranugraha@telkomuniversity.ac.id \\ S1 Sistem Informasi, Fakultas Rekayasa Industri Universitas Telkom
}

\begin{abstract}
Abstrak
Teknologi Informasi (TI) sudah menjadi inti dari suatu proses bisnis ke semua sektor termasuk sektor pemerintahan. Hal ini menuntut lembaga resmi negara di Indonesia untuk mengembangkan tata kelola TI melalui penyelenggaraan pemerintahan berbasis elektronik. Dinas Komunikasi, Informatika dan Persandian Kabupaten Sukabumi merupakan Dinas yang mempunyai tugas untuk membantu Bupati dalam melaksanakan urusan pemerintahan di Komunikasi, Informatika dan Persandian. Dalam pelaksanaannya Dinas Komunikasi, informatika dan persandian Kabupaten Sukabumi mempunyai fungsi, salah satu diantaranya adalah pengelolaan e-government daerah. Agar dapat mengetahui sejauh mana sistem tata kelola TI untuk membangun good governance berbasis e-government dibutuhkan evaluasi tata kelola teknologi informasi sesuai dengan Peraturan Presiden Nomor 95 Tahun 2018 tentang Sistem Pemerintahan Berbasis Elektronik. Dalam penelitian ini dilakukan perancangan tata kelola TI menggunakan kerangka kerja COBIT 2019 yang pada proses domain EDM04 Ensured Resource Optimization, APO12 Managed Risk, BAI08 Managed Knowledge, DSS03 Managed Problems dan MEA03 Managed Compliance with External Requirements dan menggunakan COBIT 2019 Implementation Methods sebagai metode impelementasi. Sistematika penelitian ini dimulai dengan melakukan studi dokumen dan wawancara terkait faktor desain dibantu oleh design toolkit yang mengacu pada COBIT 2019 Design Guide yang diterbitkan oleh ISACA. Setelah itu dilakukan analisis dan penilaian terhadap tingkat kapabilitas Dinas berdasarkan COBIT 2019 Governance and Management Objective. Selanjutnya pembuatan perancangan rekomendasi solusi pada aspek people,process dan technology untuk mengatasi kesenjangan berdasarkan temuan kesenjangan dari hasil penialaian kapabilitas sehingga dapat meningkatkan nilai tata kelola teknologi informasi sesuai dengan kebutuhan Dinas Komunikasi, Informatika dan Persandian Kabupaten Sukabumi.
\end{abstract}

Kata kunci : COBIT 2019; Teknologi Informasi; Tata Kelola Teknologi Informasi

\section{Pendahuluan}

Dinas komunikasi informatika atau DISKOMINFO adalah salah satu dari lembaga pemerintahan di Indonesia yang mengelola Teknologi Informasi dan Komunikasi (TIK). Salah satunya DISKOMINFOSAN Kabupaten Sukabumi. Dinas Komunikasi, Informatika dan Persandian Kabupaten Sukabumi merupakan Dinas yang mempunyai tugas untuk membantu Bupati dalam melaksanakan urusan pemerintahan yang menjadi kewenangan daerah dan tugas pembantuan di bidang komunikasi, informatika dan persandian yang mengacu pada peraturan Bupati Sukabumi Nomor 60 tahun 2016 tentang Struktur Organisasi dan Tata Kerja Dinas Komunikasi, Informatika dan Persandian Kabupaten Sukabumi. Dalam melaksanakan tugas pokok, Dinas Komunikasi, informatika dan persandian Kabupaten Sukabumi mempunyai fungsi, salah satu diantaranya adalah pengelolaan $e$ government daerah.
Permasalahan yang sedang dihadapi saat ini oleh DISKOMINFOSAN Kabupaten Sukabumi terkait pelaksanaan tugas pokok dan fungsi pelayanan yaitu kompetensi dan kualifikasi SDM Dinas Komunikasi, Informatika dan Persandian masih terbatas, belum terintegrasinya sistem pemerintahan berbasis elektronik dan keterbatasan anggaran dalam rangka pembangunan, pemeliharaan dan pengembangan SPBE. Di samping itu, DISKOMINFOSAN harus terus beradaptasi dengan perkembangan tren TIK 4.0 seperti teknologi mobile internet, cloud computing, internet of things (IoT), big data analytics dan artificial intelligence yang menjadi faktor pendorong penerapan SPBE. adanya permasalahan terhadap penerapan SPBE dan tren revolusi TIK 4.0 menghasilkan sejumlah risiko yang bisa berpengaruh pada pencapaian tujuan SPBE. Sehingga, berbagai risiko yang muncul harus dikelola dengan baik oleh DISKOMINFOSAN Kabupaten Sukabumi sebagai penyelenggara SPBE dibutuhkan 
manajemen risiko SPBE sesuai dengan Peraturan Menteri Pendayagunaan Aparatur Negara Nomor 5 Tahun 2020 tentang Pedoman Manajemen Risiko Sistem Pemerintahan Berbasis Elektronik agar DISKOMINFOSAN Kabupaten Sukabumi dapat memenuhi regulasi Peraturan Presiden Nomor 95 Tahun 2018 tentang Sistem Pemerintahan Berbasis Elektronik. Untuk meningkatkan sistem tata kelola SPBE ke tingkat yang dibutuhkan serta pengelolaan risiko dapat dilakukan melalui penggunaan model kerangka kerja yang menjadi standar penerapan teknologi informasi.

Ada beberapa model standar tentang tata kelola teknologi informasi yang diakui secara luas untuk mengetahui sejauh mana tata kelola teknologi informasi baik. Beberapa diantaranya adalah Information Technology Infrastructure Library (ITIL), Control Objectives for Information and related Technology (COBIT) dan ISO/IEC 27001. Standar-standar tersebut digunakan agar tujuan penerapan teknologi informasi di suatu organisasi sesuai dengan tujuan yang diharapkan dan terhindar dari risiko-risko kerugian yang tidak terpetakan. Dari ketiga model standar tata kelola teknologi informasi tersebut kerangka kerja yang dipilih adalah COBIT karena COBIT terbagai menjadi dua domain yaitu tata kelola dan manajemen. Tahun 2018 ISACA merilis versi COBIT terbaru yaitu COBIT 2019 yang digunakan dalam penelitian ini. Penelitian ini memberikan rekomendasi tata kelola teknologi informasi berupa aspek people, process dan technology berdasarkan kerangka kerja COBIT 2019 yang berfokus pada proses domain EDM04 Ensured Resource Optimization, APO12 Managed Risk, BAI08 Managed Knowledge, DSS03 Managed Problems dan MEA03 Managed Compliance with External Requirements yang didapatkan dari hasil 11 desain faktor untuk menyusun tata kelola TI.

\section{Metodologi Penelitian}

Metodologi penelitian yang digunakan berdasarkan COBIT 2019 Implementation Guide pada fase 1 sampai fase 5 .

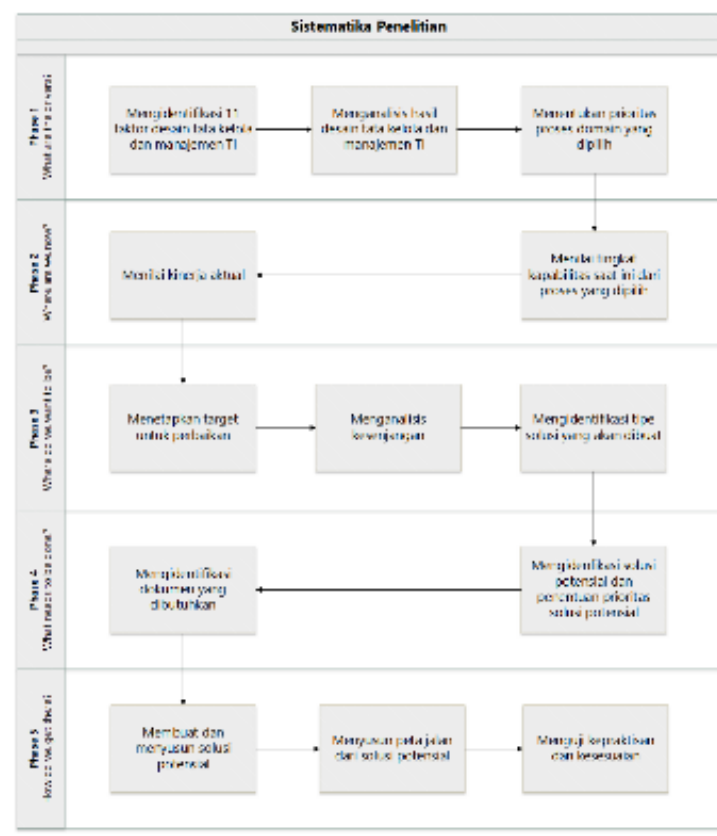

\section{Gambar 1 Sistematika Penelitian}

\section{What Are The Drivers}

Pada fase ini dilakukan identifikasi bisnis dan masalah terkait TI yang terdapat di DISKOMINFOSAN Kabupaten Sukabumi dengan bantuan design toolkit dari ISACA. Setelah mendapat hasil desain tata kelola TI lalu menentukan prioritas proses domain yang akan dipilih.

2. Where Are We Now

Pada fase ini dilakukan analisis datadata yang dibutuhkan untuk menunjang bagaimana kondisi tata kelola di Dinas Komunikasi, Informatika dan Persandian Kabupaten Sukabumi. Lalu melakukan penilaian tingkat kapabilitas dari proses domain yang dipilih. Kemudian menilai kinerja aktual.

3. Where Do We Want To Be

Pada fase ini dilakukan penentuan target perbaikan dari target yang diharapkan oleh Dinas Komunikasi, Informatika dan Persandian Kabupaten Sukabumi, dilanjutkan dengan menganalisis kesenjangan antara kondisi tata kelola sekarang dan kondisi yang diharapkan. Lalu dilakukan analisis tipe-tipe perbaikan seperti people, process dan technology.

4. What Needs To Be Done

Pada fase ini dilakukan pengembangkan tipe perbaikan melalui analisis solusi potensial yang sesuai dengan kesenjangan yang terjadi dan menentukan prioritas dari solusi potensial. Kemudian menentukan dokumen-dokumen apa saja 
yang dibutuhkan dari solusi potensial tersebut.

\section{How Do We Get There}

Pada fase ini dilakukan pembuatan dan penyusunan solusi potensial. Lalu solusi tersebut dipetakan kedalam peta jalan.

\section{Hasil dan Pembahasan}

Dalam penelitian ini, analisis yang dilakukan adalah analisis kondisi tata kelola teknologi informasi DISKOMINFOSAN Kabupuaten Sukabumi saat ini dengan kondisi ideal yang diharapkan oleh DISKOMINFOSAN Kabupaten Sukabumi, sehingga menghasilkan kesenjangan. Analisis tersebut dilakukan untuk menilai sejauh mana penerapan teknologi informasi dan menyelaraskan peran teknologi informasi dengan tujuan organisasi. Aktivitas berdasarkan COBIT 2019 Implementation Guide, COBIT 2019 Design Guide dan COBIT 2019 Governance and Management Objectives.

Pada fase 1 peneliti melakukan kegiatan wawancara menggunakan COBIT 2019 Governance System Design Toolkit dan memberikan kuisioner kepada responden. Responden kuisioner adalah divisi aplikasi dan informatika yang menangani bidang egovernment. Design Toolkit berisi indikator apa saja dari faktor yang dapat mempengaruhi desain sistem tata kelola perusahaan dan memposisikannya untuk sukses dalam penggunaan TI, terbagi menjadi 10 faktor desain yaitu Enterprise Goals, Enterprise Strategy, Risk Profile, IT Related Issues, IT Threat Landscape, Compliance Requirement, Role Of IT, IT Sourcing Model, IT Implementation Methods dan Technology Adoption Strategy. Hasil wawancara dan kuisioner berupa analisis data mengenai hasil proses domain apa saja yang akan diperbaiki.

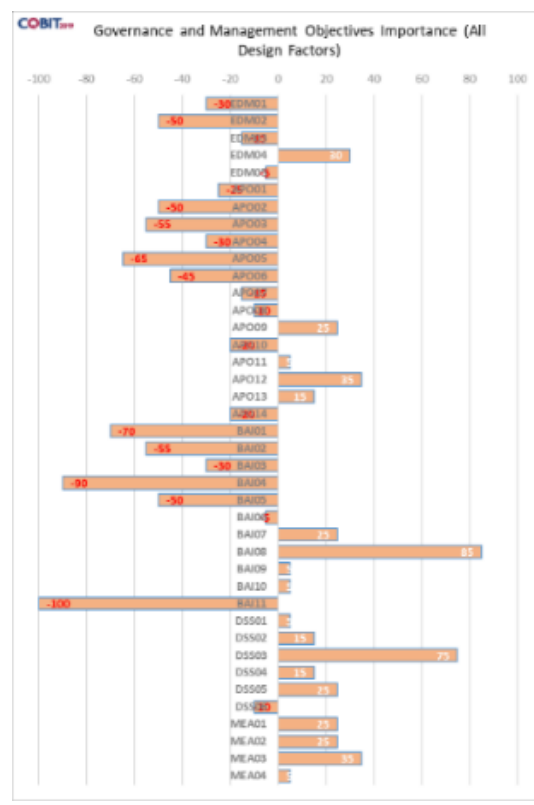

Gambar 2 Hasil Desain Faktor

Berdasarkan informasi pada gambar diatas, terdapat core model yang tersedia dalam COBIT 2019. Core model terdiri dari 40 proses domain tersebut mempunyai nilai-nilai yang berbeda karena dipengaruhi oleh nilai yang dimasukan pada design factor 1 sampai design factor 10. Rentang nilai yang didapat dari -100 hingga 95 . Nilai positif yang tertera pada desain tata kelola menandakan bahwa proses tersebut penting bagi Lembaga dan menjadi prioritas. Sementara nilai negatif menandakan bahwa proses tersebut bukan prioritas bagi Lembaga.

Pemilihan proses domain yang dipilih berdasarkan proses yang memiliki nilai lima tertinggi. Proses tersebut antara lain:

\begin{tabular}{|c|c|l|c|}
\hline Score & Domain & $\begin{array}{l}\text { Governance/Management } \\
\text { Objective }\end{array}$ & $\begin{array}{c}\text { Target } \\
\text { Capability } \\
\text { Level }\end{array}$ \\
\hline 30 & EDM04 & $\begin{array}{l}\text { Ensured Resource } \\
\text { Optimization }\end{array}$ & 2 \\
\hline 35 & APO12 & Managed Risk & 2 \\
\hline 85 & BAI08 & Managed Knowledge & 4 \\
\hline 75 & DSS03 & Managed Problems & 4 \\
\hline 35 & MEA03 & $\begin{array}{l}\text { Managed Compliance } \\
\text { with External } \\
\text { Requirements }\end{array}$ & 2 \\
\hline
\end{tabular}


Pada fase 2 dilakukan penjelasan hasil kuisioner tentang penilaian aktivitas-aktivitas pada proses domain terpilih yang sudah diisi oleh peneliti dan responden. Tujuan dari pengisian kuisioner ini adalah mengetahui kesenjangan saat ini yang nantinya dapat digunakan untuk membantu menyelesaikan kesenjangan yang ada di DISKOMINFOSAN Kabupaten Sukabumi.

Pada fase 3 dilakukan penjelasan tentang perbandingan hasil assessment capability level saat ini dengan capability level target yang sudah ditentukan. Lalu hasil perbandingan tersebut dibentuk menjadi temuan kesenjangan yang ada pada proses domain EDM04 Ensured Resource Optimization, APO12 Managed Risk, BAI08 Managed Knowledge, DSS03 Managed Problems dan MEA03 Managed Compliance with External Requirements.

Peneliti menemukan kesenjangan pada proses domain, APO12 Managed Risk, BAI08 Managed Knowledge, DSS03 Managed Problems, dan MEA03 Managed Compliance with External Requirements. Sementara EDM04 Ensured Resource Optimization tidak ditemukan kesenjangan karena seluruh pertanyaan pada kuisioner telah memenuhi atau mencapai level target sesuai COBIT 2019. Hasil analisis kesenjangan dapat dilihat pada penjabaran tabel dibawah berikut.

Keempat dan fase kelima menjelaskan tentang hasil rekomendasi peningkatan yang dibentuk dan disarankan peneliti. Fase ini dapat diharapkan agar menjadi referensi terkait peningkatan tata kelola teknologi informasi di DISKOMINFOSAN Kabupaten Sukabumi. Rekomendasi solusi terdiri dari tiga aspek yaitu people, process dan technology.

Pada aspek people berisi gambaran tentang komponen yang dibutuhkan untuk sumber daya manusia di DISKOMINFOSAN Kabupaten Sukabumi. komponen tersebut dapat diimplementasikan sebagai penunjang proses optimalisasi sumber daya TI, proses pengelolaan risiko TI, pengelolaan pengetahuan TI, pengelolaan masalah TI, dan pengelolaan kepatuhan dengan persyaratan eksternal.

Pada aspek people peneliti memberikan rekomendasi solusi berupa peran, dimana peran tersebut sangat penting terhadap eksekusi proses Managed Problems. Rekomendasi peran dapat ditambahan kedalam jobdesc Bidang APTIKA (Aplikasi Infromatika) untuk pelaksanaan pengelolaan dan pengendalian aplikasi pemerintah Kabupaten Sukabumi. Rekomendasi aspek people dapat dilihat pada tabel dibawah ini.

Pada aspek people berisi gambaran tentang komponen yang dibutuhkan untuk suatu proses yang jelas agar dapat terdokumentasikan di DISKOMINFOSAN Kabupaten Sukabumi. komponen tersebut dapat diimplementasikan sebagai penunjang proses optimalisasi sumber daya TI, proses pengelolaan risiko TI, pengelolaan pengetahuan TI, pengelolaan masalah TI, dan pengelolaan kepatuhan dengan persyaratan eksternal.

Peneliti memberikan rekomendasi solusi berupa instruksi kerja dan kebijakan. instruksi kerja direkomendasikan bagi proses Managed Problems sementara kebijakan direkomendasikan bagi proses Managed Risk, Managed Knowledge, dan Managed Compliance with External Requirement. Rekomendasi aspek process dapat dilihat pada tabel dibawah ini.

Pada aspek people berisi gambaran tentang komponen yang dibutuhkan untuk penggunaan teknologi di DISKOMINFOSAN Kabupaten Sukabumi. komponen tersebut dapat diimplementasikan sebagai penunjang proses optimalisasi sumber daya TI, proses pengelolaan risiko TI, pengelolaan pengetahuan TI, pengelolaan masalah TI, dan pengelolaan kepatuhan dengan persyaratan eksternal.

Pada aspek technology peneliti tidak memberikan rekomendasi solusi. Berdasarkan analisis peneliti bahwa DISKOMINFOSAN Kabupaten Sukabumi lebih membutuhkan tipe rekomendasi solusi policy, work instruction dan people dalam melakukan proses Ensured Resource Optimization, Managed Risk, Managed Knowledge, Managed Problems dan Managed Compliance with External Requirements.

Pada proses peja jalan impelementasi dijelaskan arahan dan linimasa dalam melakukan penyusunan rekomendasi yang diusulkan. Penyusunan peta jalan terhitung dari tahun 2022 sampai 2026 dan terbagi menjadi empat kuartal per tahun. Hal ini dilakukan agar dapat diterapkan pada Rencana Pembangunan Jangka Menengah Daerah (RPJMD) DISKOMINFOSAN Kabupaten Sukabumi periode selanjutnya yaitu tahun 2022-2026. 


\section{Kesimpulan}

Berdasarkan hasil penelitian yang dilakukan, kesimpulan yang dapat diambil dalam analisis dan perancangan tata kelola teknologi di DISKOMINFOSAN Kabupaten Sukabumi menggunakan kerangka kerja COBIT 2019 adalah :

1. Kondisi penerapan tata kelola TI di Dinas Komunikasi, Informatika dan Persandian Kabupaten Sukabumi belum optimal karena berdasarkan hasil analisis faktor desain terdapat masalah-masalah terkait TI. Selain itu, pemetaan dari hasil assessment pada proses domain EDM04 Ensured Resource Optimization, BAI08 Managed Knowledge dan DSS03 Managed Problems masih terdapat aktivitas-aktivitas pada management practice yang belum dilakukan. Bahkan pada management practice proses domain APO12 Managed Risk dan MEA03 Managed Compliance with External Requirements tidak ada aktivitas yang dilakukan sama sekali.

2. Kesenjangan penerapan tata kelola TI di Dinas Komunikasi, Informatika dan Persandian Kabupaten Sukabumi banyak ditemukan berdasarkan hasil assessment penelitian pada proses domain BAI08 Managed Knowledge, DSS03 Managed Problems, APO12 Managed Risk dan MEA03 Managed Compliance with External Requirements. Pada domain EDM04 Ensured Resource Optimization tidak ditemukan kesenjangan. Dari kesenjangan tersebut peneliti membuat rekomendasi perbaikan agar DISKOMINFOSAN Kabupaten Sukabumi dapat menerapkan tata kelola TI dengan optimal.

3. Rekomendasi untuk tata kelola TI di Dinas Komunikasi, Informatika dan Persandian Kabupaten Sukabumi pada domain APO12 Managed Risk yaitu penambahan poin kebijakan pada dokumen Peraturan Bupati Sukabumi Nomor 101 Tahun 2019 Tentang Struktur Organisasi dan Tata Kerja Dinas Komunikasi, Informatika dan Persandian dan referensi COBIT 5 for Risk. Rekomendasi untuk proses domain BAI08 Managed Knowledge yaitu penambahan poin kebijakan pada dokumen Rancangan Peraturan Daerah Kabupaten Sukabumi Tentang Penyelenggaraan Komunikasi,
Informatika Dan Persandian dan referensi Peraturan Kepala Badan Pengkajian dan Penerapan Teknologi Nomor 15 Tahun 2016 tentang Petunjuk Teknis Jabatan Fungsional Perekayasa dan Angka Kreditnya. Rekomendasi untuk proses domain MEA03 Managed Compliance with External Requirements yaitu penambahan poin kebijakan pada dokumen Rancangan Peraturan Daerah Kabupaten Sukabumi Tentang Penyelenggaraan Komunikasi, Informatika dan Persandian. Rekomendasi untuk proses domain DSS03 Managed Problems yaitu pembuatan draf dokumen tentang pedoman manajemen masalah TI. Pada proses domain EDM04 Ensured Resource Optimization tidak ada rekomendasi karena semua aktivitas di dalam management practice sudah dilakukan.

\section{Daftar Pustaka}

[1] ISACA, COBIT 2019 Implementation Guide, Schaumburg: ISACA, 2018.

[2] ISACA, COBIT 2019 Design Guide, Schaumburg: ISACA, 2018.

[3] Menteri Pendayaan Aparatur Negara, Peraturan Menteri Pendayagunaan Aparatur Negara Nomor 5 Tahun 2020 Tentang Pedoman Manajemen Risiko Sistem Pemerintahan Berbasis Eletronik, Jakarta: Pemerintah Indonesia, 2020.

[4] Dinas Komunikasi Informatika dan Persandian Kabupaten Sukabumi, Laporan Kinerja Dinas Komunikasi Informatika dan Persandian Kabupaten Sukabumi 2020, Sukabumi: Dinas Komunikasi Informatika dan Persandian Kabupaten Sukabumi, 2020.

[5] ISACA, COBIT 2019 Framework : Governance and Management Objectives, Schaumburg: ISACA, 2018.

[6] ISACA, COBIT 2019 Framework : Introduction and Technology, Schaumburg: ISACA, 2018.

[7] S. F. Bayastura, S. Krisdina and A. P. Widodo, "Analisis Dan Perancangan Tata Kelola Teknologi Informasi Menggunakan Framework Pada PT.XYZ," JIKO (Jurnal Informatika dan Komputer), vol. 4, no. 1, pp. 68-75, 2021.

[8] Y. Bachtiar, A. A. N. Fajrillah and I. Santosa, "Analisis dan Perancangan Tata 
Kelola Teknologi Informasi BUMN Pada Proses Pengelolaan Layanan dan Pengelolaan Sekuriti Teknologi Informasi Menggunakan COBIT 2019 (Studi Kasus : PT Nindya Karya (Persero))," e-Proceeding of Engineering, vol. 7, no. 2, pp. 67696769, 2020.

[9] U. F. Khusniah, L. Abdurrahman and I. Santosa, "Analisis dan Perancangan Tata Kelola Teknologi Informasi BUMN pada Proses Penetapan Peran dan Perencanaan Teknologi Informasi Menggunakan Kerangka Kerja COBIT 2019 [Studi Kasus : PT Pos Indonesia (Persero)]," $e$ Proceeding of Engineering, vol. 7, no. 2, pp. 6810-6818, 2020.

[10] Presiden Republik Indonesia, Peraturan Presiden Republik Indonesia Nomor 95
Tahun 2018 Tentang Sistem Pemerintahan Berbasis Elektronik, Jakarta: Pemerintah Indonesia, 2018.

[11] P. A. Adwiyah and L. H. Atrinawati, "Perancangan Tata Kelola Teknologi Informasi Menggunakan Framework COBIT 2019 Pada PT.XYZ," JTSI (Jurnal Teknologi dan Sistem Informasi), vol. 1, no. 2, pp. 1-9, 23 Desember 2020.

[12] ISACA, COBIT 5 for Risk, Rolling Meadows: ISACA, 2013.

[13] Kepala Badan Pengkajian dan Penerapan Teknologi, Peraturan Kepala Badan Pengkajian dan Penerapan Teknologi Nomor 15 Tahun 2016 Tentang Petunjuk Teknis Jabatan Fungsional Perekayasa dan Angka Kreditnya, Jakarta: Pemerintah Indonesia, 2016. 